\title{
Carbamylated Erythropoietin Promotes Coronary Neovascularization through Extracellular Signal Regulated Kinase Pathway in Diabetic Rats with Myocardial Infarction
}

\author{
YAN HUANG*, HONG SHENG GANG ${ }^{1}$, MING LI, B. XU AND WEN HUA LI
}

Department of Emergency, ${ }^{1}$ Department of Cardiovascular Medicine, Wuhan Fourth Hospital, Puai Hospital, Tongji Medical College, Huazhong Universiy of Science and Technology, Gutian San Lu, Wuhan, Hubei 430033, China

Huang et al.: Carbamylated Erythropoietin Promotes Coronary Neovascularization

\begin{abstract}
To investigate whether carbamylated erythropoietin can influence the coronary collateral circulation via extracellular signal regulated kinase 1/2 signaling pathway. A diabetic rat model was established. Vascular endothelial growth factor, angiotensin-I and phosphorylated-extracellular signal regulated kinase 1/2 expression were observed along with changes in hemodynamics and infarct area. The results showed that left ventricular diastolic pressure, left ventricular end diastolic pressure, maximum rate of left ventricular pressure rise, heart rate, (left ventricular systolic pressure-left ventricular diastolic pressure ${ }^{\sharp}$ )* heart rate, microvessel density and vascular endothelial growth factor were significantly decreased and the percentage of myocardial infarct size, the levels of prostacyclin, endothelin 1, angiotensin II, von Willebrand factor, phosphorylated-fibroblast growth factor receptor 2, phosphorylated-phospholipase C gamma and phosphorylated-extracellular signal regulated kinase $1 / 2$ were significantly increased in other groups compared with control group $(\mathbf{p}<\mathbf{0 . 0 5})$. Left ventricular diastolic pressure, left ventricular end diastolic pressure, maximum rate of left ventricular pressure rise, heart rate and (left ventricular systolic pressureleft ventricular diastolic pressure ${ }^{\#}$ * heart rate were significantly increased in carbamylated erythropoietin group and significantly decreased in carbamylated erythropoietin+PD98059 group compared with the sham group $(\mathbf{p}<\mathbf{0 . 0 5})$. However, the myocardial infarction size and the levels of prostacyclin, endothelin 1 , angiotensin II and von Willebrand factor were significantly decreased and the microvessel density, vascular endothelial growth factor, angiotensin-1, phosphorylated-fibroblast growth factor receptor 2, phosphorylatedphospholipase $\mathrm{C}$ gamma and phosphorylated-extracellular signal regulated kinase $1 / 2$ were significantly increased in carbamylated erythropoietin and carbamylated erythropoietin+PD98059 groups compared with the sham group $(\mathrm{p}<\mathbf{0 . 0 5})$. Amino glycosylated erythropoietin was able to improve the hemodynamics of diabetic infarct rats and there was also an extracellular signal regulated kinase 1/2 conduction pathway in the neovascularization of diabetic infarct rats. This provides a new target for future clinical use to reduce myocardial damage caused by myocardial infarction.
\end{abstract}

Key words: Erythropoietin, diabetes mellitus, heart attack, extracellular signal regulated kinase, streptozotocin

Diabetic Heart Attack (DHA), as a unique cardiovascular disease, is characterized by oxidative stress, inflammation, cardiac fibrosis and cardiomyocyte apoptosis induced myocardial relaxation and contraction dysfunction ${ }^{[1]}$. In the past few decades, the role of apoptosis in DHA has been widely concerned, that is, programmed cell death controlled by intrinsic genetic mechanism in the pathogenesis of DHA under certain physiological or pathological conditions ${ }^{[2,3]}$.

Erythropoietin (EPO), a glycoprotein cytokine produced by mammalian kidney and liver, plays an important role in stimulating the proliferation, hemoglobin and maturation of immature erythrocytes in bone marrow hematopoietic microenvironment. Since 1989, recombinant human Erythropoietin (rhEPO) has been used in the treatment of anemia caused by various clinical reasons and it has been gradually found that rhEPO also has a variety of cell protective effects ${ }^{[4-6]}$. However, the long-term and highdose application of rhEPO can affect the hematocrit in

*Address for correspondence

E-mail: h10021310@163.com 
circulation and cause side effects such as hypertension and vascular embolism, so its clinical application has certain limitations ${ }^{[7]}$.

CarbamylatedErythropoietin(CEPO) is a carbamoylated derivative of EPO. When the conformation and function of the protein are changed, CEPO with a molecular weight of about $40 \mathrm{kDa}$ can be formed ${ }^{[8,9]}$. Although CEPO did not promote erythropoiesis, it retained a variety of cell protective functions of $\mathrm{EPO}^{[10,11]}$. CEPO can prevent the release of mitochondrial contents (such as reactive oxygen species and cytochrome c) by limiting the opening of mitochondrial permeability transition pore, thus reducing cell apoptosis ${ }^{[5]}$.

In addition, CEPO can also affect cell signal transduction through Extracellular signal Regulated Kinase (ERK)$1 / 2$ pathway ${ }^{[12]}$. However, it is not clear whether CEPO can promote coronary neovascularization in DHA rats. In this study, we investigated the effect of CEPO treatment on coronary neovascularization induced by Streptozotocin (STZ) fed on a high-fat/ high carbohydrate diet in DHA rats and its underlying molecular mechanisms.

\section{MATERIALS AND METHODS}

\section{Source of reagents:}

RhEPO, STZ, Diethyl Pyrocarbonate (DEPC), sodium borate and potassium cyanate were purchased from Sigma company (Sigma, CA, USA). The Terminal deoxynucleotidyl transferase mediated dUTP Nick End Labeling (TUNEL) kit was obtained from Shanghai shanran Biotechnology Co., Ltd (Shanran Shanghai, China). Caspase-3, B-cell lymphoma extra-large (Bcl$\mathrm{xL})$, ERK-1 and ERK-2 antibodies were purchased from Cell Signaling Technology (CST, CA, USA). ERK messenger RNA (mRNA) was obtained from Shanghai Lianmai Bioengineering Co., Ltd (Lianmai Shanghai, China).

\section{Synthesis of CEPO:}

CEPO was synthesized as previously described by Khan, et al. In short, potassium cyanate is added to sodium borate containing rhEPO $(1 \mathrm{mg} / \mathrm{ml})$ and $500 \mu \mathrm{l}$ (1 $\mathrm{m}$ ) to produce a solution with a final concentration of $1 \mathrm{~mol} / \mathrm{I}^{[13]}$. They were mixed and incubated at $37^{\circ}$ for 1 $\mathrm{d}$ to form the reaction solution with in situ hybridization kit. Excess potassium cyanate was removed from the reaction solution by dialysis and then further concentrated by ultrafiltration (cut-off membrane, $10 \mathrm{kDa}$ ). The protein concentration was measured by Coomassie brilliant blue staining and the absorbance was read at $335 \mathrm{~nm}$.
A total of 100 healthy male Wistar rats from animal center of Zhongshan University were used to establish diabetic models. They were fed with high fat and high carbohydrate diet (66.6\% basic rat food, $20 \%$ sucrose, $10 \%$ lard, $3 \%$ egg yolk and $0.4 \%$ cholesterol) for 4 $\mathrm{w}$ and then intraperitoneally injected with STZ $(50 \mathrm{mg} /$ $\mathrm{kg}) .1 \mathrm{w}$ later, the same dose of STZ was injected again. According to the standard of fasting blood glucose concentration $>18 \mathrm{mmol} / \mathrm{l}$ and lasting for $1 \mathrm{w}$. Finally, 80 rats with diabetes were identified and used in the following experiments.

\section{Animal grouping:}

According to the principle of random distribution, the rats were randomly divided into four research groups: control group (only left coronary artery was threaded without ligation after thoracotomy); sham group, CEPO group and CEPO+PD98059 group; CEPO group, CEPO+PD98059 group; CEPO group, CEPO+PD98059 group, CEPO group, CEPO+PD98059 group, CEPO group, CEPO+PD98059 group, CEPO group, CEPO+PD98059 group, CEPO group. The drug was given once $30 \mathrm{~min}$ before ligation of left coronary artery and twice a week after operation (ear vein injection, $50 \mu \mathrm{g} / \mathrm{kg}$ each time); The administration method of CEPO in CEPO+PD98059 group was the same as that of CEPO group, but PD98059 $(0.3 \mathrm{mg} / \mathrm{kg}$ by ear vein injection) was given $30 \mathrm{~min}$ before ligation of left coronary artery and twice a week $(0.3 \mathrm{mg} / \mathrm{kg}$ each time) after operation. The control group was given the same dose of saline water by ear edge vein injection at the same time, 20 animals in each group.

\section{Monitoring of hemodynamic parameters in rats:}

After anesthetized rats by intraperitoneal injection of chloral hydrate, the right skin of the rat neck was cut, and the fascia, muscle and carotid sheath were separated layer by layer and the common carotid artery was separated by $1-1.2 \mathrm{~cm}$. The common carotid artery was cut by ophthalmic scissors and the catheter was inserted about 1-1.5 cm. After $15 \mathrm{~min}$, Blood Pressure (BP) and mean arterial pressure (map) were recorded. Then, Med lab-u/8C biological signal acquisition and processing system was applied to monitor the Left Ventricular Diastolic Pressure (LVDP), maximum rate of left ventricular pressure rise $\left(\mathrm{dP} / \mathrm{dt}_{\text {max }}\right)$, Left Ventricular End Diastolic Pressure (LVEDP).

\section{Measurement of infarct size:}

The infarct size was measured by 
2,3,5-Triphenyltetrazolium chloride (TTC) staining. The left ventricle was rinsed with normal saline and wrapped with tin foil and stored in a refrigerator at $20^{\circ}$. 2-3 $\mathrm{mm}$ serial sections were made from the apex to the bottom of the heart in the direction perpendicular to the long axis of the heart to the level of the ligation line. The slices were placed in TTC dye solution and dyed in $37^{\circ}$ incubator for $20 \mathrm{~min}$ and then put into 4 $\%$ formaldehyde solution for $15 \mathrm{~min}$. White infarcted myocardial tissue and brick red viable myocardial tissue could be observed after taking out the tissue. Finally, the infarct area and non-infarct area were separated with scissors and the mass of infarct area was calculated by electronic balance.

The infarct area=left ventricular infarct mass/left ventricular ligation line myocardial mass $\times 100 \%$.

\section{Enzyme-Linked Immunosorbent Assay (ELISA):}

The antigens (prostacyclin (PGI2), Endothelin 1 (ET1), angiotensin II (Ang II), von Willebrand Factor (vWF)) were diluted to $10 \mu \mathrm{g} / \mathrm{ml}$ with coated buffer and overnight at $4^{\circ}$. The next day, add $0.1 \mathrm{ml}$ serum of rats in each group into the coated reaction pore and incubate at $37^{\circ}$ for $1 \mathrm{~h} ; 0.1 \mathrm{ml}$ fresh diluted enzyme labeled second antibody was added and incubated at $37^{\circ}$ for 30 min; then $0.1 \mathrm{ml}$ tetramethylbenzidine (TMB) substrate solution was added and incubated at $37^{\circ}$ for $10 \mathrm{~min}$. Finally, add $0.05 \mathrm{ml} 2 \mathrm{~mol} / 1$ sulfuric acid to determine the Optical Density (OD value) at $450 \mathrm{~nm}$ wave length of ELISA detector. Meanwhile, the OD values of PGI2, ET-1, Ang II and vWF were determined and calculated in each group.

\section{The Microvessel Density (MVD) was measured by immunohistochemistry:}

In this study, vascular endothelium was labeled with CD34 and MVD was counted by immunohistochemistry. The infarct area was determined according to the existing studies ${ }^{[14]}$. $5 \mu \mathrm{m}$ thick myocardial tissue was reserved at the junction of infarct area (gray white, wall thinning) and non-infarct area (pink). The frozen section ( $2 \mathrm{~mm}$ below the ligation line) was made in the sham operation group. The myocardium of each group was fixed, transparent, waxed, embedded, dewaxed and hydrated. After incubation overnight at $4^{\circ}$, each slice was incubated with $50 \mu 1$ of ready to use maxvision reagent at room temperature for $15 \mathrm{~min}$ and then $100 \mu 1$ of freshly prepared Diaminobenzidine (DAB) solution was added. Under the microscope, the number of endothelial cells or clusters of endothelial cells stained brown was counted as a blood vessel and the vessels in the lumen with more than 8 red blood cells Special Issue 5, 2021 Indian Journal of Pharmaceutical Sciences and thicker muscular layer were not counted. Under the microscope of $400 \mathrm{x}$ visual field, 5 visual fields were randomly selected from each section to count the number of microvessels (MVC) in the infarct border area and the average value was obtained. MVC in each field was MVD.

\section{The expression of Vascular Endothelial Growth Factor (VEGF) and Ang-1 was detected by immunohistochemistry:}

Paraffin sections of myocardial tissue were routinely dewaxed, hydrated and high-pressure antigen repair, then diluted primary antibody (rabbit anti-VEGF 1:50, rabbit anti-rat Ang-1 antibody 1:100) was dropped at $37^{\circ}$ for $2 \mathrm{~h}$ and washed with Phosphate Buffered Saline (PBS) three times. After that, the second antibody was incubated at room temperature for $15 \mathrm{~min}$, washed with PBS for 3 times then dyed with DAB developer and hematoxylin. Taking the presence of brown particles in the cytoplasm or extracellular matrix of cardiac myocytes as the positive criterion, six visual fields were randomly selected under high power microscope (400 times) and their Integral Absorbance (IA) was counted respectively by automatic image analysis system and the numerical mean value was analyzed.

\section{Western blot analysis:}

After adding $30 \mathrm{mg}$ fresh myocardial tissue into $100 \mu \mathrm{l}$ tissue lysate for $1 \mathrm{~h}$, the $\gamma$ supernatant was centrifuged and the protein was quantified by Bicinchoninic acid (BCA) protein concentration quantitative kit. After Sodium Dodecyl-Sulfate Polyacrylamide Gel Electrophoresis (SDS-PAGE) electrophoresis, $50 \mu \mathrm{g}$ protein/well was transferred to Polyvinylidene Fluoride (PVDF) membrane. $5 \%$ bovine serum albumin (BSA) was sealed at room temperature for $2 \mathrm{~h}$. The working solutions of Fibroblast Growth Factor Receptors (FGFR), phosphorylated-fibroblast growth factor receptors (p-FGFR2), phosphorylated-phospholipase C gamma (p-PLC $\gamma$ ), phosphorylated ERK1/2 (p-ERK1/2), FGFR2, PLC, ERK1/2 and $\beta$-actin were prepared and sealed overnight at $4^{\circ}$ and that was washed three times at room temperature. Then incubated with Horseradish Peroxidase (HRP) labeled second antibody working solution for $2 \mathrm{~h}$. The E lectrochemiluminescence (ECL) working fluid was exposed to the high performance luminescent gel imaging system. The gray scale of the strips was calculated by image J software and the relative expression intensity of phosphoprotein was detected by the ratio of phosphorylated protein to total protein. 


\section{Statistical analysis:}

Statistical Package For The Social Sciences (SPSS) 22.0 software system was used in present study and expressed as data $\mathrm{x} \pm \mathrm{s}$. Analysis of Variance (ANOVA) was used to compare the data more than three groups and $\mathrm{t}$ test was used for pairwise comparison between two groups. $p<0.05$ was considered to be statistically significant.

\section{RESULTS AND DISCUSSION}

Compared with the control group, LVDP, LVEDP, $\pm \mathrm{dP} /$ $\mathrm{dt}_{\max }$, heart rate $(\mathrm{HR})$ and $\left(\right.$ LVSP-LVDP $\left.{ }^{\#}\right) \times \mathrm{HR}$ were significantly lower in sham, CEPO and CEPO+PD98059 groups $(p<0.05)$. Compared with the sham group, the LVDP, LVEDP, $\pm \mathrm{dP}^{\mathrm{dt}}{ }_{\text {max }}$, HR and (LVSP-LVDP ${ }^{*} \times \mathrm{HR}$ were significantly higher in CEPO group $(p<0.05)$ and significantly lower in CEPO group, as shown in fig. 1.

Compared with the control group, the percentage of myocardial infarct size in sham, CEPO and CEPO+PD98059 groups were significantly higher $(p<0.05)$. However, the myocardial infarction size in CEPO and CEPO+PD98059 groups were significantly lower than that in sham group $(\mathrm{p}<0.05)$. In addition, compared with the control group, the MVD in sham, CEPO and CEPO+PD98059 groups were significantly lower $(\mathrm{p}<0.05)$ and the MVD in CEPO and CEPO+PD98059 groups were significantly higher than that in sham group $(\mathrm{p}<0.05)$. As shown in fig. 2 .
Compared with the control group, the levels of PGI2, ET1, Ang II and vWF in sham, CEPO and CEPO+PD98059 groups were significantly increased $(p<0.05)$. Compared with the sham group, the levels of PGI2, ET-1, Ang II, vWF in CEPO and CEPO+PD98059 groups were significantly decreased $(p<0.05)$, suggesting that CEPO can improve the coronary microcirculation function of diabetic rats. The detection results of PGI2, ET-1, Ang II, vWF levels in peripheral serum of rats in each group are shown in fig. 3 .

Compared with the control group, the expression of VEGF and Ang-1 in sham, CEPO and CEPO+PD98059 groups were significantly decreased $(p<0.05)$. Compared with the sham group, the expression of VEGF and Ang-1 were significantly increased in CEPO and CEPO+PD98059 groups $(\mathrm{p}<0.05)$. The detection results of VEGF and Ang-1 expression in muscle tissue of rats in each group are shown in fig. 4.

Compared with the control group, the expression of p-FGFR2, p-PLC $\gamma$, p-ERK1/2 proteins in CEPO and CEPO+PD98059 groups were significantly increased $(\mathrm{p}<0.05)$, but there is no significantly difference in sham group ( $>0.05$ ). Compared with the sham group, the expression of p-FGFR2, p-PLC $\gamma$, p-ERK1/2 proteins were further increased in CEPO and CEPO+PD98059 groups $(\mathrm{p}<0.05)$. As shown in fig. 5 .
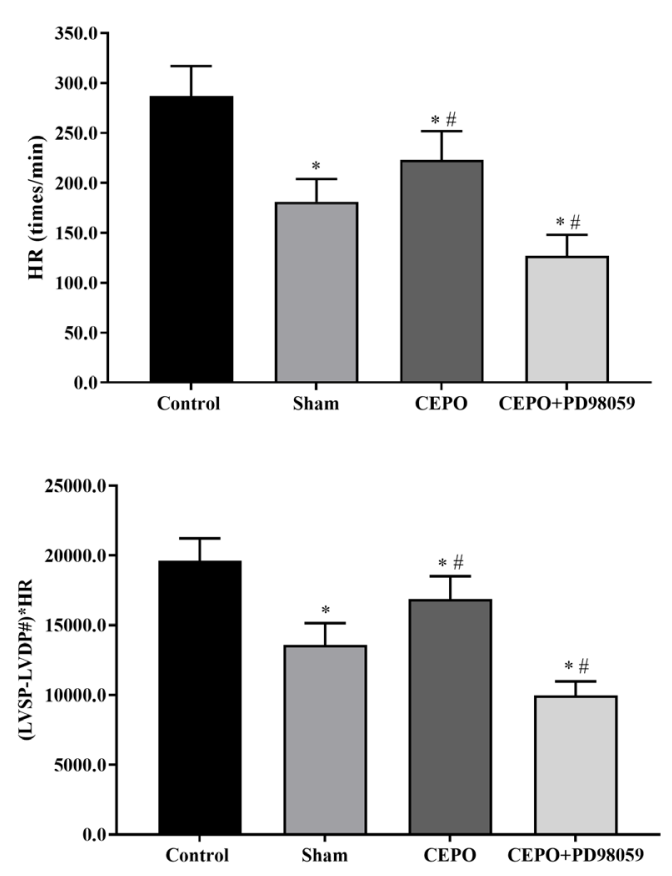

Fig. 1: Hemodynamic parameters of rats in four groups

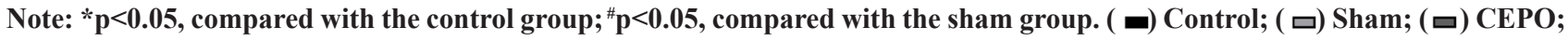
(口) CEPO+PD98059 

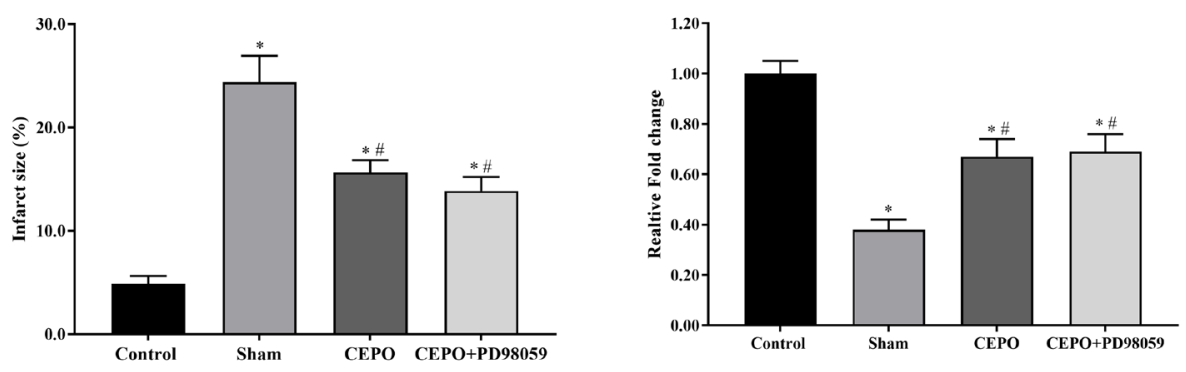

Fig. 2: Myocardial infarct size and MVD of rats in four groups

Note: * $p<0.05$, compared with the control group; ${ }^{*} p<0.05$, compared with the sham group

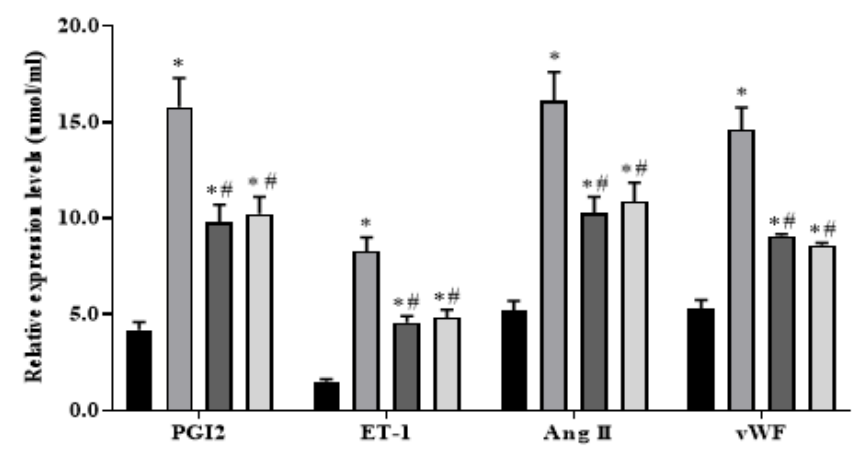

Fig. 3: Changes of microcirculation markers in four groups

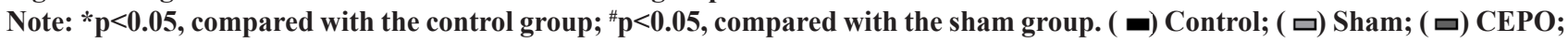
(口) CEPO+PD98059

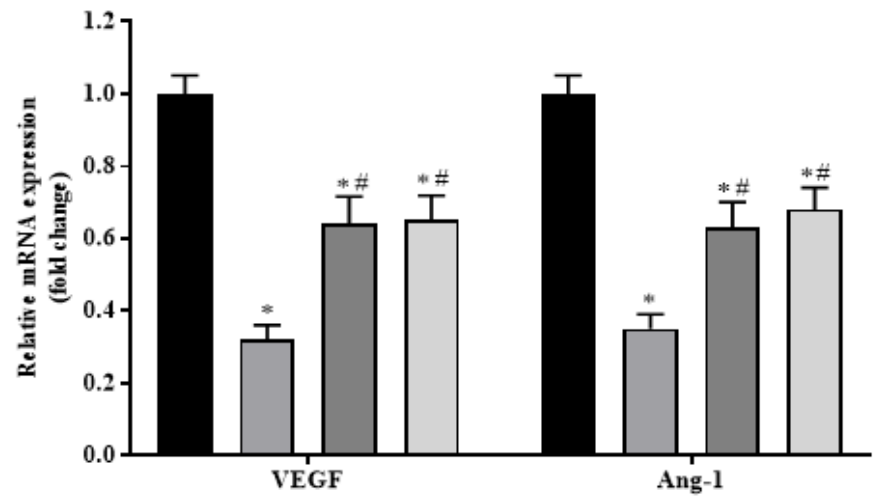

Fig. 4: The expression of VEGF and Ang-1 in four groups

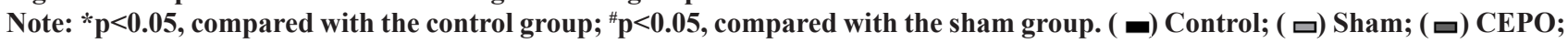
(口) CEPO+PD98059

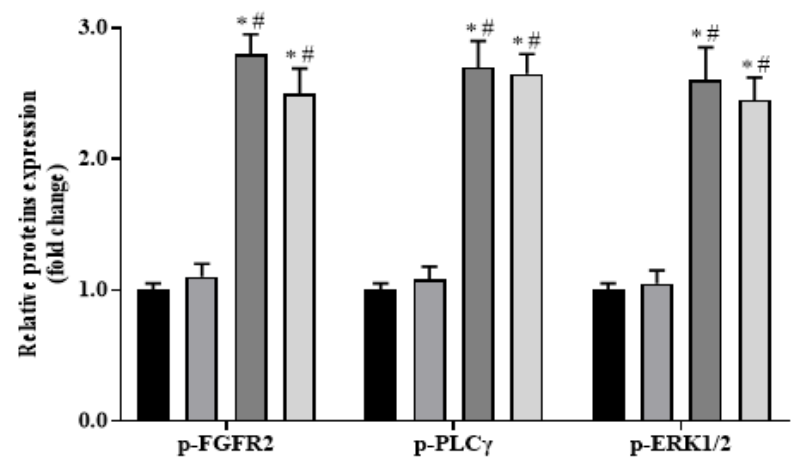

Fig. 5: The protein expression levels of p-FGFR2, p-PLC $\gamma$, p-ERK1/2 in four groups

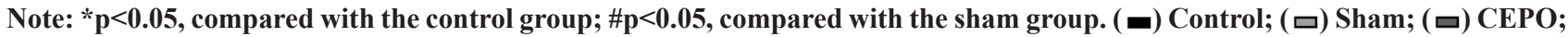
(口) CEPO+PD98059 
Diabetes, as one of the major diseases threatening human health, its complications are an important factor to reduce the prognosis of patients, among which cardiovascular and cerebrovascular complications are the most common cause of death in patients with diabetes $^{[4]}$. Although oral hypoglycemic drugs and insulin can greatly alleviate the patient's condition, there are still many side effects. Therefore, it is of great significance to formulate effective strategies for the prevention and treatment of diabetes. Diabetic cardiomyopathy is mainly caused by high blood glucose and coronary microcirculation hypoperfusion. In view of the fact that myocardial activity largely depends on the supply of microcirculation oxygen, nutrients and the transport of metabolites, restoring coronary microcirculation is an important way to improve myocardial activity ${ }^{[14-16]}$.

In this study, we used Med Lab-U/8C, a biological signal acquisition and processing system, to directly monitor the physical indicators of cardiac work and evaluate the real-time cardiac function. LVDP and the maximum rate of rise of left ventricular pressure $\left(+\mathrm{dP} / \mathrm{dt}_{\max }\right)$ are important indicators to reflect cardiac systolic function. The decrease of LVDP and $+\mathrm{dP} / \mathrm{dt}_{\max }$ indicates the decrease of myocardial systolic function. In addition, the LVEDP and the maximum rate of decrease of left ventricular pressure $\left(-\mathrm{dP} / \mathrm{dt}_{\max }\right)$ are important indicators to reflect cardiac diastolic function. The increase of LVEDP or the decrease of $-\mathrm{dP} / \mathrm{dt}_{\max }$ indicates the decrease of cardiac diastolic function; (Left Ventricular Systolic Pressure-Left Ventricular Diastolic Pressure $\times$ heart rate $\left(\right.$ LVSP-LVDP $\left.{ }^{\#}\right) \times$ HR reflects the contractile force of myocardium. The results showed that after ligation of left anterior descending coronary artery, the systolic and diastolic functions of the heart decreased to varying degrees, which was reflected in the decrease of left ventricular development pressure and the maximum rise rate of left ventricular pressure, while the end diastolic pressure increased and the maximum decline rate of left ventricular pressure decreased, which was consistent with the previous research results ${ }^{[17]}$. Pretreatment and postconditioning with ecop can significantly improve LVDP, LVEDP, $\pm \mathrm{dp} / \mathrm{dt}_{\text {max }}$ and other indicators of the heart, that is, significantly improve the cardiac systolic and diastolic function, which is similar to the findings of Apstein.

ERK are a class of serine/threonine protein kinases, whose main function is to transmit mitogen signal transduction proteins ${ }^{[18,19]}$. ERK is the key to transmit signal from surface receptor to nucleus. Phosphorylated
ERK 1/2 is transferred from cytoplasm to nucleus, which mediates transcription activation of various cytokines, regulates cell proliferation and differentiation, cell morphology maintenance, cytoskeleton construction, cell apoptosis and cell malignant transformation and other biological processes. Hyperglycemia cannot only cause myocardial injury through the formation of advanced glycation end products, but also cause a variety of vascular complications by stimulating the proliferation of vascular smooth muscle ${ }^{[20]}$, which can be attenuated by the activation of ERK signaling pathway. In diabetic rats with myocardial infarction, the activation of ERK cell signaling pathway is closely related to myocardial cell anti apoptosis ${ }^{[21]}$. The effect of hyperglycemia on ERK phosphorylation in cardiomyocytes is also time-dependent and short-term hyperglycemia can enhance ERK phosphorylation ${ }^{[22,23]}$. Recent studies have shown that CEPO can activate ERK cell signaling pathway to protect myocardium from ischemia/reperfusion injury ${ }^{[24,25]}$. In chronic hypoxia, CEPO may reduce the levels of PGI2, ET1, Ang II, vWF in peripheral serum to near normal level through ERK signal pathway ${ }^{[10]}$. In this study, we demonstrated that CEPO could protect myocardium against myocardial fibrosis and apoptosis by activating p-ERK signaling pathway.

Myocardial infarction can lead to hypoxia in body tissues and cause changes in local cytokine levels, induce the proliferation, migration, lumen formation and formation of new blood vessels of vascular endothelial cells with existing vessels, so as to adaptively increase blood supply and oxygen supply. During this process, abnormal secretion of cytokines, especially angiogenesis factor VEGF and basic fibroblast growth factor (bFGF), occurred. bFGF, a basic protein, has the effect of promoting cell mitosis and promoting angiogenesis. After binding with its specific receptor FGFR, bFGF can activate tyrosine kinase in vascular endothelial cells, thus activating PLC $\gamma^{[6]}$. PLC $\gamma$ is the most important member of the four phosphoinositol specific phospholipase C (PLC $\beta$, $\operatorname{PLC} \gamma$, PLC $\delta$ and PLC $\varepsilon$ ), which are widely expressed in vascular endothelial cells. Phosphorylation is the key factor to regulate PLC $\gamma$ activity. In the process of bFGF and other factors activating vascular endothelial cells, PLC $\gamma$ can form receptor complex with FGFR2, further activate ERK1/2 signaling pathway protein downstream, start endothelial cell proliferation and generate neovascular endothelial cells. In this study, we found that CEPO can significantly promote bFGF induced phosphorylation of receptor and downstream 
cell signaling pathway proteins, which may be one of the mechanisms of CEPO promoting angiogenesis.

In conclusion, carbamoyl erythropoietin can improve the hemodynamics of diabetic myocardial infarction rats and regulate ERK $1 / 2$ pathway in promoting neovascularization of diabetic myocardial infarction rats, which provides a new target for clinical medication to reduce myocardial injury caused by myocardial infarction.

\section{Acknowledgement:}

This work was supported by the foundation of Scientific Research Project of Wuhan Municipal Health and Family Planning Commission (No. WX16B13).

\section{Conflict of interests:}

The authors declared no conflicts of interest.

\section{REFERENCES}

1. Gurav AN. Management of diabolical diabetes mellitus and periodontitis nexus: Are we doing enough?. World J Diabetes 2016;7(4):50.

2. Schöffel N, Börger JA, Quarcoo D. Erythropoietin -state of science. Sportverletz Sportschaden 2008;22(4):201.

3. Xu K, George I, Klotz S, Hay I, Xydas S, Zhang G, et al. Erythropoietin derivate improves left ventricular systolic performance and attenuates left ventricular remodeling in rats with myocardial infarct-induced heart failure. J Cardiovasc Pharmacol 2010;56(5):506-12.

4. Sanchis-Gomar F, Garcia-Gimenez JL, Pareja-Galeano H, Romagnoli M, Perez-Quilis C, Lippi G. Erythropoietin and the heart: physiological effects and the therapeutic perspective. Int J Cardiol 2014;171(2):116-25.

5. Ogunshola OO, Bogdanova AY. Epo and non-hematopoietic cells: what do we know? Tissue-Protective Cytokines 2013:1341.

6. He H, Qiao X, Wu S. Carbamylated erythropoietin attenuates cardiomyopathy via PI3K/Akt activation in rats with diabetic cardiomyopathy. Exp Ther Med 2013;6(2):567-73.

7. Fantacci M, Bianciardi P, Caretti A, Coleman TR, Cerami A, Brines $\mathrm{M}$, et al. Carbamylated erythropoietin ameliorates the metabolic stress induced in vivo by severe chronic hypoxia. Proc Natl Acad Sci U S A 2006;103(46):17531-6.

8. Moon C, Krawczyk M, Paik D, Coleman T, Brines M, Juhaszova M, et al. Erythropoietin, modified to not stimulate red blood cell production, retains its cardioprotective properties. J Pharmacol Exp Ther 2006;316(3):999-1005.

9. Robey TE, Saiget MK, Reinecke H, Murry CE. Systems approaches to preventing transplanted cell death in cardiac repair. J Mol Cell Cardiol 2008;45(4):567-81.

10. Fiordaliso F, Chimenti S, Staszewsky L, Bai A, Carlo E, Cuccovillo I, et al. A nonerythropoietic derivative of erythropoietin protects the myocardium from ischemiareperfusion injury. Proc Natl Acad Sci U S A 2005;102(6):204651.

11. Aragno $\mathrm{M}$, Mastrocola $\mathrm{R}$, Medana $\mathrm{C}$, Catalano $\mathrm{MG}$, Vercellinatto I, Danni O, et al. Oxidative stress-dependent impairment of cardiac-specific transcription factors in experimental diabetes. Endocrinology 2006;147(12):5967-74.
12. Raja L, Palanivelu S, Panchanatham S. Anti-inflammatory property of Kalpaamruthaa on myocardium in type 2 diabetes mellitus induced cardiovascular complication. Immunopharmacol Immunotoxicol 2013;35(1):119-25.

13. Khan R. Examining potential therapies targeting myocardial fibrosis through the inhibition of transforming growth factorbeta 1. Cardiology 2007;108(4):368-80.

14. Ma YX, Li WH, Xie Q. Rosuvastatin inhibits TGF-beta 1 expression and alleviates myocardial fibrosis in diabetic rats. Pharmazie 2013;68(5):355-8.

15. Piuhola J, Kerkela R, Keenan JI, Hampton MB, Richards AM, Pemberton CJ. Direct cardiac actions of erythropoietin (EPO): effects on cardiac contractility, BNP secretion and ischaemia/ reperfusion injury. Clin Sci 2008;114(4):293-304.

16. Madonna R, Shelat H, Xue Q, Willerson JT, Caterina RD, Geng YJ. Erythropoietin protects myocardin-expressing cardiac stem cells against cytotoxicity of tumor necrosis factor-alpha. Exp Cell Res 2009;315(17):2921-8.

17. Carraway MS, Suliman HB, Jones WS, Chen CW, Babiker A, Piantadosi CA. Erythropoietin activates mitochondrial biogenesis and couples red cell mass to mitochondrial mass in the heart. Circ Res 2010;106(11):1722-30.

18. Li R, Liang T, Xu L, Li Y, Zhang S, Duan X. Protective effect of cinnamon polyphenols against STZ-diabetic mice fed highsugar, high-fat diet and its underlying mechanism. Food Chem Toxicol 2013;51:419-25.

19. Zhang M, Lv XY, Li J, Xu ZG, Chen L. The characterization of high-fat diet and multiple low-dose streptozotocin induced type 2 diabetes rat model. Exp Diabetes Res 2008;2008:704045.

20. Panagia M, Gibbons GF, Radda GK, Clarke K. PPARalpha activation for decreased glucose uptake and increased susceptibility to injury during ischemia. Am J Physiol Heart Circ Physiol 2005;288(6):H2677-83.

21. Silverberg DS, Wexler D, Iaina A, Schwartz D. The interaction between heart failure and other heart diseases, renal failure and anemia. Semin Nephrol 2006;26(4):296-306.

22. Bilim O, Takeishi Y, Kitahara T, Arimoto T, Niizeki T, Sasaki $\mathrm{T}$, et al. Diacylglycerol kinase zeta inhibits myocardial atrophy and restores cardiac dysfunction in streptozotocin-induced diabetes mellitus. Cardiovasc Diabetol 2008;7:2.

23. Naito Z, Takashi E, Xu G, Ishiwata T, Teduka K, Yokoyama $\mathrm{M}$, et al. Different influences of hyperglycemic duration on phosphorylated extracellular signal-regulated kinase $1 / 2$ in rat heart. Exp Mol Pathol 2003;74(1):23-32.

24. Yang J, Han Y, Sun H, Chen C, He D, Guo J, et al. (-)-Epigallocatechin gallate suppresses proliferation of vascular smooth muscle cells induced by high glucose by inhibition of PKC and ERK1/2 signalings. J Agric Food Chem 2011;59(21):11483-90.

25. Guleria RS, Singh AB, Nizamutdinova IT, Souslova T, Mohammad AA, Kendall Jr JA, et al. Activation of retinoid receptor-mediated signaling ameliorates diabetes-induced cardiac dysfunction in Zucker diabetic rats. J Mol Cell Cardiol 2013;57:106-18.

This is an open access article distributed under the terms of the Creative Commons Attribution-NonCommercial-ShareAlike 3.0 License, which allows others to remix, tweak, and build upon the work non-commercially, as long as the author is credited and the new creations are licensed under the identical terms

This article was originally published in a special issue, "Diagnostic and Therapeutic Advances in Biomedical Research and Pharmaceutical Sciences"

Indian J Pharm Sci 2021:83(5) spl issue “62-68” 